\title{
THE ROLE OF PRETREATMENT PARAMETERS ON SEED GERMINATION AND SEEDLING GROWTH OF TWO FENNEL CULTIVARS
}

\author{
M. KHOSHKHARAM ${ }^{1, *}$, M.H. SHAHRAJABIAN ${ }^{2, *}$, W. SUN ${ }^{2}$, Q. CHENG ${ }^{2,3}$ \\ *E-mail: mehdi.khoshkharam@gmail.com; hesamshahrajabian@gmail.com
}

Received: May 11, 2020. Revised: June 17, 2020. Accepted: June 25, 2020. Published online: July 18, 2020

\begin{abstract}
Fennel is one of the most important medicinal and spice plants and has become one of the most important economical medicinal plants in Mediterranean, and the Middle East. The germination ability and percentage are fundamental characteristics which influence the viability of the plants. Prechilling has meaningful influence on coleoptile length, radicle length, seedling length, germination percentage, mean time for germination and germination rate, but uniformity of seed germination did not significantly influenced by it. The cultivar effect was significant on coleoptile length, radicle length, seedling length, germination percentage and germination rate. However, mean time for germination and uniformity of seed germination did not significantly affected by cultivar. All experimental characteristics, except uniformity of seed germination, significantly influenced by hormone. The maximum coleoptile length, radicle length, seedling length,
\end{abstract}

germination percentage and germination ratio was related to 45 days moist prechilling treatment. Isfahan cultivar also had obtained the highest coleoptile and radicle length, seedling length, germination percentage and germination ratio compare to Shiraz cultivar. It seems that application of endogenous $\mathrm{GA}_{3}+\mathrm{KI}$ and $\mathrm{BA}+\mathrm{KI}$ concentration, which is provided mostly by chilling treatment, is the most effective factor for breaking the seed dormancy. On the basis of the results, usage of 45 days moist prechilling accompanied with application of $\mathrm{GA}_{3}+\mathrm{KI}$ and $\mathrm{BA}+\mathrm{KI}$ in Isfahan cultivar was appropriate.

Keywords: kinetin; gibberellic acid; benzyladenine; germination percentage; germination rate.

\section{INTRODUCTION}

Herbs due to having natural antioxidant compounds are widely

\footnotetext{
${ }^{1}$ Department of Agronomy and Plant Breeding, Faculty of Agriculture, Islamic Azad University, Isfahan (Khorasgan) Branch, Isfahan, Iran

2 Biotechnology Research Institute, Chinese Academy of Agricultural Sciences, Beijing 100081, China

${ }^{3}$ College of Life Sciences, Hebei Agricultural University, Baoding, Hebei, 071000, China; Global Alliance of HeBAU-CLS\&HeQiS for BioAl-Manufacturing, Baoding, Hebei 071000, China
} 


\section{KHOSHKHARAM, M.H. SHAHRAJABIAN, W. SUN, Q. CHENG}

used by food, pharmaceutical and cosmetics industries (Soleymani and Shahrajabian, 2012a,b; Ogbaji et al., 2013; Soleymani et al., 2013; Shahrajabian et al., 2019a,b,c; Sun et al., 2019a; Sun et al., 2020a,b). Traditional herbs and plant have several therapeutic and pharmaceutical effects and also valuable natural food resources (Soleymani et al.,2012; Ge et al., 2018; Shahrajabian et al., 2019d,e,f,g; Ogbaji et al., 2018; Sun et al., 2019b,c; Shahrajabian et al., 2020a,b).

Fennel (Foeniculum vulgare L.) is a herb with galactogogues property, which belongs to the Umbelliferae and its root, leaf, fruit and seed are used (Soleymani and Shahrajabian, 2012a; Ghasemiet al., 2014; Maghsoudi Kelardashti et al., 2015). It is a popular medicinal plant with various pharmacological activities in both traditional Iranian and Chinese medicine (Rahimi and Shams Ardekani, 2012; Bokaie et al., 2013; Maghsoudi Kelardashti et al., 2015).

The germination ability and percentage are fundamental characteristics, which influence the viability of the plants developing from the grains (Soleymani and Shahrajabian, 2018). Sharifi and Pouresmael (2006) concluded that only cold treatments and gibberellic acid, cytokinin, potassium nitrate, washing and light treatments are not useful. Nkomo and Kambizi (2010) noted that prechilling, followed by exposure to a temperature higher than $30^{\circ} \mathrm{C}$ encourages germination of Corchorus olitorius seeds.
Rouhi et al. (2010) concluded that applying $500 \mathrm{ppm}$ concentration of $\mathrm{GA}_{3}$ and 0.1 of $\mathrm{KNO}_{3}$ resulted in highergermination in waterlily dormant seeds. Plant hormones are used in breaking seed dormancy (Gupta et al., 2008). Growth regulator, GA is effective in breaking seed dormancy in snowberry (Symphoricarpos albus) (Rosner, 2002). Although black cumin (Nigella sativa) is an important and expensive medicinal and spice plant, no information is available on the effects of moist prechilling and application of hormones on different cultivars of it. So, the aim of this study is survey the certain effects of different treatments to stimulate seed germination and seedling growth of two masses of black cumin. The aim of this research is to evaluate the certain effects of different treatments to stimulate seed germination and seedling growth of two cultivars of fennel.

\section{MATERIALS AND METHODS}

In order to determine the effects of some pretreatment factors on primary growth and germination characteristics of two cultivars of fennel, an experiment was conducted as Split-factorial layout within completely randomized design at Seed Research laboratory, Islamic Azad University, Khorasgan (Isfahan) branch in 2015. Most pre-chilling treatments were $0,15,30$ and 45 days treatments and cultivars were consisted of Isfahan and Shiraz. Hormone treatments were $\mathrm{GA}_{3}$, $\mathrm{BA}, \mathrm{KI}, \mathrm{GA}_{3}+\mathrm{BA}, \mathrm{GA}_{3}+\mathrm{KI}, \mathrm{BA}+\mathrm{KI}$, $\mathrm{GA}_{3}+\mathrm{BA}+\mathrm{KI}, \mathrm{KNO}_{3}, \mathrm{H}_{2} \mathrm{SO}_{4}$ and distilled water as a control treatment. Firstly, seeds were surface sterilized in $1.5 \%(\mathrm{w} / \mathrm{v})$ 
sodium hypochlorite solution for $15 \mathrm{~min}$ and rinsed three times sterile distilled water. For each treatment, four Petri dishes were used and 25 seeds were put into each of them, then, each Petri dish were covered with $10 \mathrm{~mm}$ of each specific treatment. In the first experiment, seeds were chilled for 15,30 and 45 days, and after this period, seeds were soaked and treated with 10 hormone treatments. In the second experiment, seeds were treated without pre-chilling treatments. In the third experiment, seeds treatments were done with polyethylene glycol. Germination percentage and germination rate was calculated with equation number 1 and 2, respectively. The mean separation was made using Duncan's multiple range test at 0.05 probability. Mean of replications was used for statistical analysis.

$$
\begin{aligned}
\text { Germination percentage } & =\text { Number of germinated seed } / 100 \\
\operatorname{Vg} & =\Sigma(\mathrm{Ni} / \mathrm{Di}), \quad(2)
\end{aligned}
$$

where, $\mathrm{Vg}$ : germination rate on the basis of number of seeds per day; Ni: germinated seed per day; Di: day number after the beginning of experiment.

$$
\begin{aligned}
\text { Uniformity of seed germination }=\frac{1}{\frac{\sum(\mathrm{D}-\overline{\mathrm{D}})^{2} \times \mathrm{N}}{\Sigma \mathrm{N}}} \\
\qquad \mathrm{MTG}=\frac{\Sigma(\mathrm{nd})}{\Sigma \mathrm{n}}, \quad(4)
\end{aligned}
$$

Uniformity of seed germination and mean time for seed germination (MTG) was evaluated by equations 3 and 4 .

where, $n=$ number of germinated seed in the specific day; $d=$ number of days from the beginning of germination; $\Sigma \mathrm{n}=$ total number of germinated seed.

\section{RESULTS AND DISCUSSION}

Prechilling has meaningful influence on coleoptile length, radicle length, seedling length, germination percentage, mean time for germination and germination rate, but uniformity of seed germination did not significantly influenced by it.

The cultivar effect was significant on coleoptile length, radicle length, seedlinglength, germination percentage and germination rate. However, mean time for germination and uniformity of seed germination did not significantly affected by cultivar. All experimental characteristics, except uniformity of seed germination, significantly influenced by hormone. The highest coleoptile length was related to 45 days chilling treatments, which had significant differences with all other treatments. This treatment also obtained the maximum radicle length, but just had significant differences with 0 and 15 days chilling treatments. Germination percentage was significantly increased from 0 to 45 days chilling treatments. The maximum and the minimum mean time for germination was related to 30 and 0 days chilling treatments. Germination rate also increased significantly from 0 to 45 days of chilling treatments. All differences among treatments about germination rate were significant. Germination is the most sensitive stage in the life cycles of a plant and 


\section{KHOSHKHARAM, M.H. SHAHRAJABIAN, W. SUN, Q. CHENG}

perfect and uniform germination is essential to have an appropriate green area and crop growth rate that will get better radiation and increase the yield (Ashraf and Mehmood, 1990). There were no significant differences between moist chilling treatments about uniformity of seed germination. Gupta et al. (2008) reported that prechilling treatment also improved seed germination in isabgol (Psyllium husk).

The highest coleoptile length $(1.656 \mathrm{~mm})$, radicle length $(0.9288$ $\mathrm{mm})$, seedling length $(2.484 \mathrm{~mm})$, germination percentage (55.46\%) and germination rate (3.541) was related to Isfahan, which had meaningful difference with Shiraz cultivar. Although, the maximum mean time for germination and uniformity of seed germination was obtained for Isfahan, there were no significant differences between Isfahan and Shiraz. The highest coleoptile length and radicle length was related to $\mathrm{GA}_{3}+\mathrm{KI}$ and BA, respectively. The highest and the lowest seedling length also were obtained by KI. BA+Ki treatment had obtained the highest germination percentage, which had significant differences with all other treatments except of BA. The highest mean time for germination and germination rate was related to $\mathrm{GA}_{3}+\mathrm{BA}$ and $\mathrm{BA}+\mathrm{KI}$, respectively. There were no significant differences in uniformity of seed germination among hormone treatments (Table 1). Gupta et al. (2008) concluded that GA has shown promising effect in breaking seed dormancy, with accelerated seed germination (speed of germination, vigor index) and seedling growth (seedling dry weight). On the basis of the results, usage of 45 days moist prechilling, accompanied with application of $\mathrm{GA}_{3}+\mathrm{KI}$ and $\mathrm{BA}+\mathrm{KI}$ in Isfahan cultivar was appropriate.

\section{CONCLUSION}

Prechilling had significant effect on coleoptile length, radicle length, seedling length, germination percentage, mean time for germination and germination rate. Cultivar also had significant influence on coleoptile length, radicle length, seedling length, germination percentage and germination rate of fennel seeds. All experimental characteristics, except uniformity of seed germination, significantly influenced by hormone. The maximum coleoptile length, radicle length, seedling length, germination percentage and germination ratio was related to 45 days moist prechilling treatment. Isfahan cultivar had obtained the highest coleoptile and radicle length, seedling length, germination percentage and germination ratio, compare to Shiraz cultivar. Application of endogenous $\mathrm{GA}_{3}+\mathrm{KI}$ and $\mathrm{BA}+\mathrm{KI}$ concentration, which is provided mostly by chilling treatment, is the most effective factor for breaking the seed dormancy. On the basis of the results, usage of 45 days moist prechilling, accompanied with application of $\mathrm{GA}_{3}+\mathrm{KI}$ and $\mathrm{BA}+\mathrm{KI}$ in Isfahan cultivar, was appropriate. 


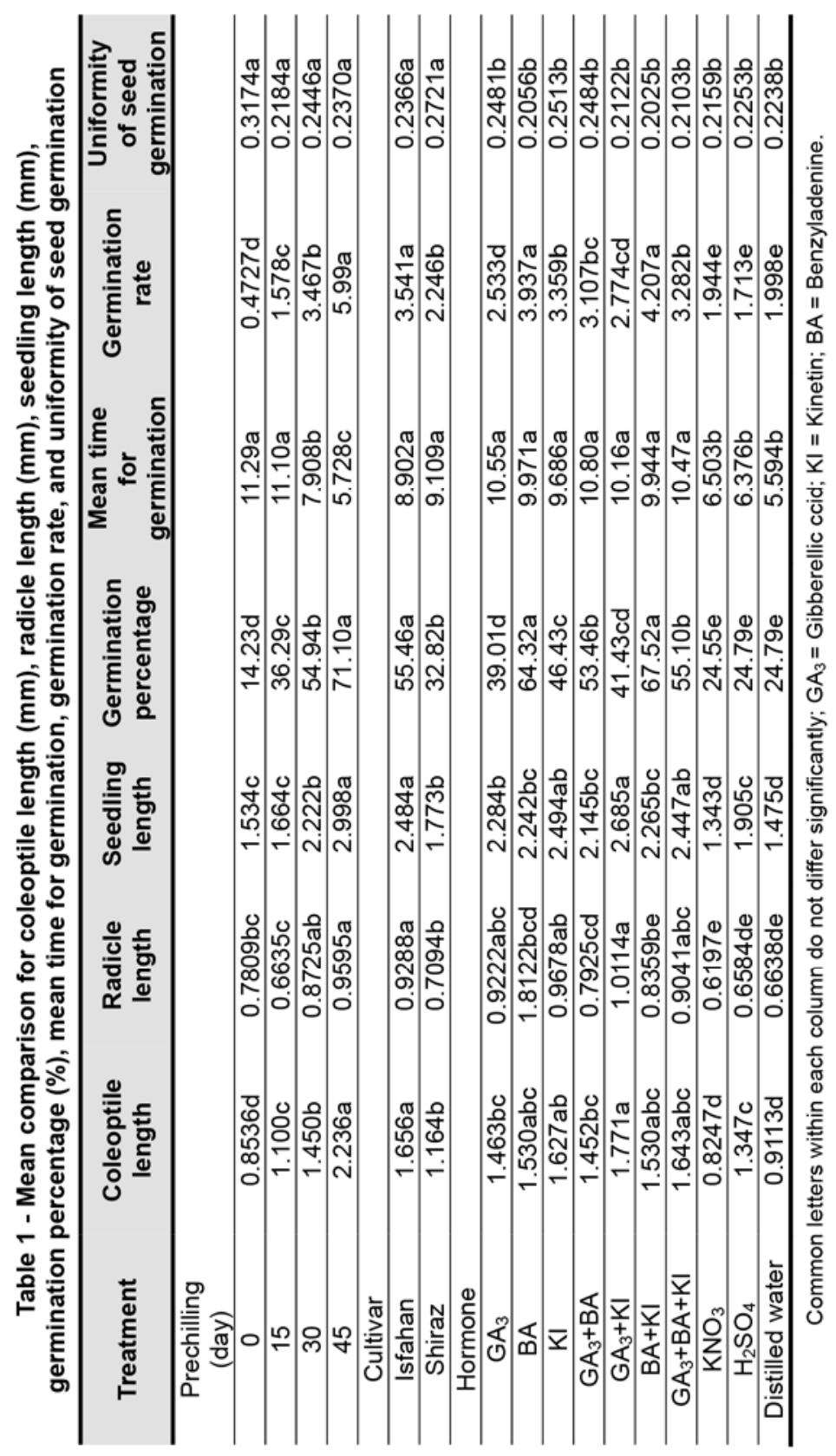




\section{KHOSHKHARAM, M.H. SHAHRAJABIAN, W. SUN, Q. CHENG}

\begin{abstract}
Germination and seedling establishment from laboratory experiments does not necessarily mean that germination and seedling emergence from the field soils, so more field experiments are needed and seed dormancy is one of the major problems in studies
\end{abstract}

\section{REFERENCES}

Ashraf, M. \& Mehmood, S. (1990). Response of four Brassica species to drought stress. Environ.Exp.Bot., 30(1): 93-100, DOI: 10.1016/00988472(90)90013-T

Bokaie, M., Farajkhoda, T., Enjezab, B., Khoshbin, A. \& Mojgan, K.Z. (2013). Oral fennel (Foeniculum vulgare) drop effect on primary dysmenorrheal: effectiveness of herbal drug. Iran.J.Nurs. Midwifery Res., 18(2): 128-132.

Ge, J., Hu, Y., Ren, C., Guo, L., Wang, C., Sun, W. \& Shahrajabian, M.H. (2018). Effects of $\mathrm{GA}_{3}$, and $A B A$ on the germination of dormant oat seeds. Cercet.Agron. in Moldova, 51(3): 25-41, DOI: 10.2478/cerce2018-0023

Ghasemi, V., Kheirkhah, M., Samani, L.N. \& Vahedi, M. (2014). The effect of herbal tea containing fennel seed on breast milk sufficiency signs and growth parameters of Iranian infants. Shiraz E-Med.J., 15(4): e22262, DOI: $10.17795 / \mathrm{semj} 122262$

Gupta, A., Parihar, S.S., Choudhary, V.K., Naseem, M. \& Maiti, R.K. (2008). Germination, dormancy and its removal in isabgol (Plantago ovata Forssk). Int.J.Agric.Environ. Biotech, 1(3): 117-124.

Khoshkharam, M., Shahrajabian, M.H., Sun, W. \& Cheng, Q. (2019). Survey the allelopathic effects of tobacco (Nicotiana tabacum L.) on corn (Zea mays L.) growth and germination. Cercet.Agron. in Moldova, 4(180): 332-340, DOI: 10.2478/cerce-2019-0032

Khoshkharam, M., Shahrajabian, M.H., Sun, W. \& Cheng, Q. (2020). Sumac (Rhus coriaria L.), a spice and medicinal plant - a mini review. Amazon.J. Plant Res., 4(2): 517523, DOI: 10.26545/ajpr.2020.b000 $61 \mathrm{x}$

Maghsoudi Kelardashti, H., Rahimmalek, M. \& Talebi, M. (2015). Genetic diversity in Iranian fennel (Foeniculum vulgare Mill.) populations based on sequence related amplified polymorphism (SRAP) markers. J.Agr.Sci.TechnIran, 17: 1789-1803.

Nkomo, M. \& Kambizi, L. (2010). Germination studies on Corchorus olitorius L. (Tiliaceae) (Jew's Mallow), a wild leafy vegetable for possible domestication in the Eastern Cape, South Africa. Asp.Appl.Biol., 96: 55-59.

Ogbaji, P.O., Shahrajabian, M.H. \& Xue, $X$. (2013). Changes in germination and primarily growth of three cultivars of tomato under diatomite and soil materials in auto-irrigation system. Int.J.Biol., 5(3): 80-84, DOI: 10.5539/ijb.v5n3p80

Ogbaji, P,O,, Li, J., Xue, X., Shahrajabian, M.H. \& Egrinya, E.A. (2018). Impact of bio-fertilizer or nutrient solution on spinach (Spinacea oleracea) growth and yield in some province soils of P.R. China. CercetAgron. in Moldova, 51(2): 43-52, DOI: 10.2478/cerce2018-0015

Rahimi, R. \& Shams Ardekani, M.R. (2012). Medicinal properties of Foeniculum vulgare Mill. in traditional Iranian medicine and modern phytotherapy. Chin.J.Integr. Med., 19: 73-79, DOI: 10.1007/s116 55-013-1327-0

Rosner, L.S., Harrington, J.T., Dreesen, D.R. \& Murray, I. (2002). Effect of gibberellic acid and standard seed treatments on mountain snowberry 
germination. Native Plants J., 3(2): 155-162.

Rouhi, H.R., Shakarami, K. \& Tavakkol Afshari, R. (2010). Seed treatments to overcome dormancy of waterlily tulip (Tulipa kaufmanniana Regel.). Aust.J. Crop Sci., 4(9): 718-721.

Shahrajabian, M.H., Sun, W. \& Cheng, Q. (2019a). Climate change, acupuncture and traditional Chinese herbal medicines. Pharmacogn. Comm., 9(3): 91-95, DOI: 10.5530/ pc.2020.1.x

Shahrajabian, M.H., Sun, W. \& Cheng, Q. (2019b). Sustainable agriculture and soybean, a legume in traditional Chinese medicine with great biological nitrogen fixation. J.Biol.Environ.Sci., 13(38): 71-78.

Shahrajabian, M.H., Sun, W. \& Cheng, Q. (2019c). Chinese star anise and anise, magic herbs in traditional Chinese medicine and modern pharmaceutical science. Asian J.Med.Biol.Res., 5(3): 162-179, DOI: 10.3329/ajmbr.v5i3.43584

Shahrajabian, M.H., Sun, W. \& Cheng, Q. (2019d). DNA methylation as the most important content of epigenetics in traditional Chinese herbal medicine. J.Med. Plant Res., 13(16): 357-369, DOI: 10.5897/JM PR2019.6803

Shahrajabian, M.H., Sun, W. \& Cheng, Q. (2019e). Modern pharmacological actions of Longan fruits and their usages in traditional herbal remedies. J.Med. Plants Stud., 7(4): 179-185.

Shahrajabian, M.H., Sun, W. \& Cheng, Q. (2019f). Clinical aspects and health benefits of ginger (Zingiber officinale) in both traditional Chinese medicine and modern industry. ActaAgr.Scand.B-S P, DOI: 10.1080/ 09064710/2019.1606930

Shahrajabian, M.H., Sun, W. \& Cheng, Q. (2019g). A review of ginseng species in different regions as a multipurpose herb in traditional Chinese medicine, modern herbology and pharmacological science. J.Med. Plant Res., 13(10): 213-226, DOI: 10.5897/JMPR2019. 6731

Shahrajabian, M.H., Sun, W. \& Cheng, Q. (2020a). Chinese star anise (Illicium verum) and pyrethrum (Chrysanthemum cinerariifolium) as natural alternatives for organic farming and health care - a review. Aust.J. Crop Sci., 14(03): 517-523.

Shahrajabian, M.H., Khoshkharam, M., Sun, W. \& Cheng, Q. (2020b). The impact of manganese sulfate on increasing grain yield, protein and manganese content of wheat cultivars in semi arid region. J. Stress Physiol.Biochem., 16(1): 76-79.

Sharifi, M. \& Pouresmael, M. (2006). Breaking seed dormancy in Bunium persicum by stratification and chemical substances. Asian J. Plant Sci., 5(4): 695-699, DOI: 10.3923/ ajps.2006.695.699

Soleymani, A. \& Shahrajabian, M.H. (2012a). Response of different cultivars of fennel (Foeniculum vulgare) to irrigation and planting dates in Isfahan, Iran. Res.Crop., 13(2): 656-660.

Soleymani, A. \& Shahrajabian, M.H. (2012b). Study of cold stress on the germination and seedling stage and determination of recovery in rice varieties. Int.J.Biol., 4(4): 23-30, DOI: 10.5539/ijb.v4n4p23

Soleymani, A., Khoshkharam, M. \& Shahrajabian, M.H. (2012). Germination rate and initial growth of silage corn grown under various fertility systems. Res.Crop., 13(3): 1035-1038.

Soleymani, A., Shahrajabian, M.H. \& Naranjani, L. (2013). Effect of planting dates and different levels of nitrogen on seed yield and yield components of nuts sunflower (Helianthus annuus L.). Afr.J.Agric.Res., 8(46): 5802-5805, DOI: 10.5897/AJAR11.255

Soleymani, A. \& Shahrajabian, M.H. (2018). Changes in germination and 


\section{KHOSHKHARAM, M.H. SHAHRAJABIAN, W. SUN, Q. CHENG}

seedling growth of different cultivars of cumin to drought stress. Cercet.Agron. in Moldova, 51(1): 91100, DOI: 10.2478/cerce-2018-0008

Sun, W., Shahrajabian, M.H. \& Cheng, Q. (2019a). The insight and survey on medicinal properties and nutritive components of shallot. J.Med. Plant Res., 13(18): 452-457, DOI: 10.5897/JMPR2019.6836

Sun, W., Shahrajabian, M.H. \& Cheng, Q. (2019b). Therapeutic roles of goji berry and ginseng in traditional Chinese. J.Nutr. Food Secur., 4(4): 293-305, DOI: 10.18502/jnfs.v4i4. 1727

Sun, W., Shahrajabian, M.H. \& Cheng, Q. (2019c). Anise (Pimpinella anisum I.), a dominant spice and traditional medicinal herb for both food and medicinal purposes. Cogent Biol., 5(1): 1-25, DOI: 10.1080/23312025.2019.1673688

Sun, W., Shahrajabian, M.H. \& Huang, Q. (2020a). Soybean seeds treated with single walled carbon nanotubes (SwCNTs) showed enhanced drought tolerance during germination. Int. J.Adv.Biol.Biomed. Res., 8(1): 9-16, DOI: 10.33945/ SAMI/IJABBR.2020.1.2

Sun, W., Shahrajabian, M.H., Khoshkharam, M. \& Cheng, Q. (2020b). Adaptation of acupuncture and traditional Chinese herbal medicines models because of climate change. J. Stress Physiol. Biochem., 16(1): 85-90. 